\title{
Effects of a best-possible-self mental imagery exercise on mood and dysfunctional attitudes
}

Citation for published version (APA):

Renner, F., Schwarz, P., Peters, M. L., \& Huibers, M. J. H. (2014). Effects of a best-possible-self mental imagery exercise on mood and dysfunctional attitudes. Psychiatry Research, 215(1), 105-110. https://doi.org/10.1016/j.psychres.2013.10.033

Document status and date:

Published: 01/01/2014

DOI:

10.1016/j.psychres.2013.10.033

Document Version:

Publisher's PDF, also known as Version of record

Document license:

Taverne

Please check the document version of this publication:

- A submitted manuscript is the version of the article upon submission and before peer-review. There can be important differences between the submitted version and the official published version of record.

People interested in the research are advised to contact the author for the final version of the publication, or visit the DOI to the publisher's website.

- The final author version and the galley proof are versions of the publication after peer review.

- The final published version features the final layout of the paper including the volume, issue and page numbers.

Link to publication

\footnotetext{
General rights rights.

- You may freely distribute the URL identifying the publication in the public portal. please follow below link for the End User Agreement:

www.umlib.nl/taverne-license

Take down policy

If you believe that this document breaches copyright please contact us at:

repository@maastrichtuniversity.nl

providing details and we will investigate your claim.
}

Copyright and moral rights for the publications made accessible in the public portal are retained by the authors and/or other copyright owners and it is a condition of accessing publications that users recognise and abide by the legal requirements associated with these

- Users may download and print one copy of any publication from the public portal for the purpose of private study or research.

- You may not further distribute the material or use it for any profit-making activity or commercial gain

If the publication is distributed under the terms of Article $25 \mathrm{fa}$ of the Dutch Copyright Act, indicated by the "Taverne" license above, 


\title{
Effects of a best-possible-self mental imagery exercise on mood and dysfunctional attitudes
}

\author{
Fritz Renner ${ }^{a, *}$, Patrick Schwarz ${ }^{a}$, Madelon L. Peters ${ }^{a}$, Marcus J.H. Huibers ${ }^{a, b}$ \\ a Department of Clinical Psychological Science, Maastricht University, P.O. Box 616, 6200 MD Maastricht, The Netherlands \\ ${ }^{\mathrm{b}}$ Department of Clinical Psychology, VU University Amsterdam, The Netherlands
}

\section{A R T I C L E I N F O}

\section{Article history:}

Received 11 January 2013

Received in revised form

16 October 2013

Accepted 19 October 2013

Available online 1 November 2013

Keywords:

Best possible self

Mental imagery

Positive and negative affect

Dysfunctional cognitions

Mood induction

\begin{abstract}
A B S T R A C T
Dispositional optimism has been related to positive physical and mental health outcomes, increased positive mood ratings and cognitions about the future. In order to determine the causal relation between optimism and mood and cognitions optimism should be manipulated experimentally. The current study tested the effects of a best-possible-self mental imagery exercise on affect and mood ratings and dysfunctional cognitions following a sad mood induction in undergraduate students $(N=40)$. Participants in the experimental condition wrote about their best possible self in the future for $15 \mathrm{~min}$ and engaged in a mental imagery task about their best possible self in the future for $5 \mathrm{~min}$ in order to experimentally induce optimism. Participants in the control condition wrote about a typical day for $15 \mathrm{~min}$ and engaged in mental imagery about a typical day for $5 \mathrm{~min}$. We assessed affect, mood and dysfunctional cognitions before and after the experimental manipulation. Participants in the experimental condition had higher positive mood ratings and higher positive affect compared to participants in the control condition. Participants in the control condition reported decreased dysfunctional cognitions whereas dysfunctional cognitions in the experimental group remained unchanged. Future studies should replicate these findings in clinical groups with more profound levels of negative affect and dysfunctional cognitions.

(c) 2013 Elsevier Ireland Ltd. All rights reserved.
\end{abstract}

\section{Introduction}

Cognitive theories of depression emphasize the role of dysfunctional cognitive processing in the development and maintenance of depression (Beck, 1964; Abramson et al., 1978). In Beck's cognitive model of depression, negative beliefs about the self, the world, and the future are at the core of depression, whereas the reformulated learned helplessness theory emphasizes the importance of a pessimistic attributional style, defined as interpreting negative events as internal, stable, and global. Numerous studies have shown that depressed individuals are characterized by increased dysfunctional attitudes (Haaga et al., 1991), whereas relatively fewer studies have investigated the impact of positive biases such as increased optimism about the future (Taylor and Brown, 1988) on mood and dysfunctional cognitions.

Optimism can be defined as a tendency for generalized positive outcome expectancies in the future (Carver et al., 2010). Previous studies have established positive relations between optimism and physical and mental health outcomes (Segerstrom et al., 1998; Taylor et al., 2000; Rasmussen et al., 2009). For example, Segerstrom et al. (1998) found that dispositional and situational

\footnotetext{
*Corresponding author. Tel.: +31 43 3881594; fax: +31 433884155 .

E-mail address: Fritz.Renner@Maastrichtuniversity.nl (F. Renner).
}

optimism was related to more positive mood ratings and more positive immune parameters in college students. Moreover, longitudinal studies have shown that increased optimism is related to a lower incidence of depression symptoms (Giltay et al., 2006).

While these studies suggest that there is a positive relation between optimism and mental and physical health, the correlational design of these studies does not allow for any causal interpretations of the relation between optimism and outcomes. In order to establish a causal relation optimism needs to be manipulated experimentally. It has been shown previously that the vividness of positive mental imagery of the future is associated with optimism, suggesting that imagery exercises are a powerful way to increase optimism and thereby mental wellbeing (Blackwell et al., 2013). In line with this, previous experimental studies that used imagery exercises to induce optimism found that imagery of positive future events indeed increased optimism and positive mood ratings (Sheldon and Lyubomirsky, 2006; Peters et al., 2010; Meevissen et al., 2011). Moreover, one previous study has shown that a negative mood induction decreases optimism in women, suggesting that the relation between mood and optimism is bi-directional (Lewis et al., 1995). Meevissen et al. (2011) investigated the effects of daily practicing a positive future imagery exercise over a period of 2 weeks on participants' mood. In this study participants were instructed to imagine themselves in the future when everything has turned out in the best possible 
way. It was shown that the imagery exercise led to increased optimism already after the first session and at the 2 week followup assessment (Meevissen et al., 2011).

While previous studies suggest that optimism has a positive effect on mood, the impact of optimism on negative cognitions remains unclear. One way to study the impact of optimism on dysfunctional cognitions in healthy participants is to trigger dysfunctional cognitions by means of a negative mood induction paradigm. Previous studies have shown that mood induction paradigms reliably increase negative mood (Martin, 1990) and trigger dysfunctional thinking patterns in people vulnerable for depression (Miranda et al., 1990; Scher et al., 2005). Yet, to the best of the authors' knowledge, no published study to date has addressed the impact of optimism on mood or dysfunctional attitudes following a sad mood induction procedure. Thus while previous studies have shown that optimism has an effect on positive affect (e.g., Peters et al., 2010), it remains unclear whether optimism can reinstate positive affect following a sad mood induction.

The aims of the current study were to replicate and extend previous findings by studying the effects of a best-possible-self (BPS) mental imagery exercise on affect, mood and dysfunctional cognitions in healthy participants that were experimentally set into a negative mood state. Previous studies have already shown that the BPS exercise reliably increases optimism (Peters et al., 2010; Meevissen et al., 2011; Hanssen et al., 2013; Peters et al., 2013). To the best of the authors' knowledge the current study is the first to test the effects of the BPS exercise on the reinstatement of positive affect, mood and dysfunctional attitudes following a sad mood induction. We hypothesized that (1) following a sad mood induction, participants in the BPS condition would report higher levels of positive affect/mood and lower levels of negative affect/mood compared to participants in the control condition. Moreover, we hypothesized that (2) following a negative mood induction, participants in the BPS condition report lower levels of dysfunctional attitudes, compared to participants in the control condition, as measured by the dependency and perfectionism subscales as well as by the total score of the Dysfunctional Attitudes Scale.

\section{Methods}

\subsection{Participant}

Participants were forty undergraduate students from Maastricht University (32 women, eight men; age range 19-38 years, $M=22.1$ ). The study protocol was approved by the local ethics committee and all participants included in the study provided written informed consent.

\subsection{Materials}

\subsubsection{Dysfunctional Attitude Scale (DAS)}

The DAS (Weissman and Beck, 1978) is a 40-item self-report questionnaire designed to measure dysfunctional attitudes on a 7 point scale ranging from $1=$ "fully disagree" to 7 = "fully agree". For each statement, participants are asked to indicate in how far they agree with that statement in general. In the present study an abbreviated, 17-item version of the DAS (de Graaf et al., 2009) was used that measures dysfunctional attitudes along two subscales: perfectionism and dependency. An example of a perfectionism item is "If I do not do well all the time, people will not respect me" (item 4 of the original 40-item DAS). An example of a dependency item is "My value as a person depends greatly on what others think of me" (item 19 of the original 40-item DAS). The perfectionism subscale has 11 items with scores ranging from 11-77 and the dependency subscale has six items with scores ranging from 6 to 42. In the present study the scale was adapted to a $100 \mathrm{~mm}$ Visual Analog Scale (VAS) to prevent memory effects during repeated administration. Good scale score reliability (coefficient alpha $=0.91$ ) and convergent validity of the DAS-17 has been reported (de Graaf et al., 2009). In the current study reliability coefficient alpha was 0.81 for the perfectionism subscale and 0.77 for the dependency subscale.

\subsubsection{Positive and Negative Affect Schedule (PANAS)}

The PANAS (Watson et al., 1988) consists of 10 positive and 10 negative adjectives that are rated on a Likert-Type scale. In the current study the Dutch version of the PANAS was used (Engelen et al., 2006) and the scale was adapted to a $100 \mathrm{~mm}$ VAS to prevent memory effects during repeated administration. Participants were asked to rate the degree to which they feel at this specific moment for each item on a VAS scale ranging from "very slightly or not at all" to "extremely". We used the state version of the PANAS. The specific instructions that the participant received were "Please indicate how you feel at this specific moment." In the present study reliability coefficient alpha was 0.85 for the positive affect scale and 0.91 for the negative affect scale.

\subsubsection{Mood scales}

VAS were used to measure current mood state of participants. The four mood scales measured mood on a bipolar continuum between positive and negative, dull and glad, anxious and secure, and happy and sad. Participants rated their relative position between each of these pairs on a $100 \mathrm{~mm}$ scale. These four scales were chosen in order to capture broader aspects of positive and negative mood states.

\subsubsection{Negative mood induction}

The negative mood induction consisted of mood suggestive music ("Adagio for Strings" by Samuel Barber) in combination with autobiographical recall. All participants were instructed to recall a sad event from their lives while listening to the music via a headphone for $10 \mathrm{~min}$. During the mood induction procedure the experimenter was sitting behind a room divider and was not visible to the participant. Mood suggestive music in combination with autobiographical recall is a reliable method to induce short lasting negative mood states (Martin, 1990).

Best-possible-self imagery exercise. In order to experimentally manipulate optimism we used a mental imagery task that has previously been validated as an effective paradigm to manipulate optimism (Peters et al., 2010). Participants in the experimental condition were instructed to imagine their BPS in the future whereas participants in the control condition were instructed to imagine a typical day. In both conditions participants where first instructed to think about the task for one minute. Then participants in the experimental condition were asked to write about their BPS for 15 min whereas participants in the control condition were asked to write about a typical day for $15 \mathrm{~min}$. In both groups participants were instructed to keep writing and if necessary repeat what they already wrote. Finally, participants were asked to engage in mental imagery about their best possible self in the future/a typical day for $5 \mathrm{~min}$. Participants were explicitly instructed to visualize their mental image as vividly as possible and with as much detail as possible. A more detailed description of the optimism induction paradigm and the specific instructions are provided by Sheldon and Lyubomirsky (2006) and by Peters et al. (2010).

\subsection{Procedure}

Participants who responded to written advertisements of the study were invited to a behavioral lab at the University and randomly assigned to either the optimism condition or to the control condition. After informed consent participants completed the first set of the PANAS and the mood scales. After completion of these questionnaires, all participants received the negative mood induction consisting of mood suggestive music in combination with autobiographical recall for $10 \mathrm{~min}$ Following the negative mood induction participants again completed the PANAS and the mood scales as well as the DAS. Next the experimental manipulation was conducted. Participants in the experimental condition received the BPS instructions whereas participants in the control condition received the instructions for the control condition. Following the experimental manipulation, the PANAS, mood scales and DAS were again administered. At the end of the experiment participants received a gift voucher of 7.50 Euro.

\subsection{Statistical analyse}

Paired sample $t$-tests were used to determine the effect of the mood induction (manipulation check). Moreover, we conducted a repeated measures ANOVA on the affect|mood scales with time as within group factor (pre-mood induction to postmood induction) and condition as between group factor. The purpose of these analyses was to determine whether the mood induction had a similar impact on mood and affect in the two conditions. To determine the effect of the BPS exercise on positive and negative affect (hypothesis 1), two one-way ANOVAs with the positive and negative affect change score as dependent variables and condition as a between-subjects factor were conducted. The same analyses were conducted with the mood scales as dependent variable. To determine the effect of the BPS exercise on dysfunctional attitudes three one-way ANOVAs with the dependency and perfectionism subscales and the DAS total score as dependent variable and condition as between subject factor were conducted. 


\section{Results}

\subsection{Baseline characteristics}

Participants who were randomized to the experimental condition did not differ from participants randomized to the control condition with respect to age (Mean age control group: 22.2, S. D. $=3.43$; Mean age experimental group: 22.0, S.D.=4.30; $(t(39)=-0.16, p=0.87))$, baseline scores on the four mood scales (all $p$-values $>0.05$ ) or on the positive and negative affect scales (all $p$-values $>0.05$ ). Gender was equally distributed among the two conditions $\chi^{2}(1, N=40)=2.5, p=0.14$.

\subsection{Mood induction manipulation check}

First, mood and affect ratings before the negative mood induction paradigm were compared to mood and affect ratings following the negative mood induction paradigm to check whether the manipulation was effective. The results of the paired sample $t$-test are summarized in Table 1 . There was a statistically significant decrease on all mood scales following the negative mood induction, indicating that mood decreased on average following the negative mood induction. Moreover, there was a statistically significant decrease in positive affect $(t(39)=-6.18, p<0.001)$ whereas negative affect remained stable $(t(39)=-0.02, p=0.98)$.

Next we conducted a time $\times$ condition repeated measure ANOVA on each mood scale and on the positive affect and negative affect scales from pre-mood induction to post-mood induction with condition as between subject factor. For all mood scales we found significant interactions between the within subject factor

Table 1

Mean change in mood and positive and negative affect following the mood induction.

\begin{tabular}{llll}
\hline Parameter & $\begin{array}{l}\text { Before mood induction } \\
M(\text { S.D. })\end{array}$ & $\begin{array}{l}\text { After mood induction } \\
M(\text { S.D. })\end{array}$ & $t(39)$ \\
\hline Mood scales & & & \\
$\quad$ Positive-negative & $21.95(14.49)$ & $44.08(16.81)$ & $8.46^{* *}$ \\
Glad-dull & $31.90(15.99)$ & $53.87(17.49)$ & $7.16^{* *}$ \\
Secure-anxious & $29.50(15.99)$ & $39.07(17.88)$ & $2.71^{*}$ \\
Happy-sad & $22.05(15.73)$ & $48.68(18.52)$ & $8.53^{* *}$ \\
& & & \\
PANAS & & $53.80(16.41)$ & $6.18^{* *}$ \\
Positive affect & $67.46(12.55)$ & $20.84(17.64)$ & 0.02 \\
Negative affect & $20.87(16.63)$ & & \\
\hline
\end{tabular}

PANAS = Positive Affect Negative Affect Schedule; range scores 0-100; higher scores on the mood scales represent more negative mood; higher scores on the positive affect scale of the PANAS represent more positive affect whereas higher scores on the negative affect scale of the PANAS represent more negative affect.

$$
* p<0.05 \text {. }
$$$$
* * p<0.01
$$

time and the between subject factor condition, except for the secure-anxious scale (positive-negative: $F(1,38)=7.08, p=0.01$; glad-dull: $F(1,38)=6.10, p=0.02$; happy-sad: $F(1,38)=7.64$, $p=0.01)$. Inspection of the profile plots of the significant interactions revealed that participants in the experimental condition on average experienced a stronger decrease in mood following the sad mood induction compared to participants in the control condition. For the PANAS the interaction between the within subject factor time and the between subject factor condition was not significant for the negative affect scale $(F(1,38)=0.82, p=0.37)$ or the positive affect scale $(F(1,38)=0.97, p=0.33)$ indicating that the effect of the mood induction on affect did not differ between participants randomized to the experimental or control condition.

\subsection{Correlations among study variables}

Correlations among the study variables after the mood induction are presented in Table 2 . All mood scales correlated negatively with the positive affect scale and positively with the negative affect scale, except for the secure-anxious scale which was unrelated to positive and negative affect. The positive-negative and the glad-dull mood scales and the negative affect scale correlated positively with the perfectionism subscale of the DAS. The negative affect scale also correlated positively with the DAS total score. The other mood and affect scales were unrelated to the DAS.

\subsection{Effect of the BPS exercise on positive and negative affect (hypothesis 1)}

In order to test hypothesis 1 , we evaluated change in positive and negative affect and change in negative mood in participants who received the BPS exercise and in participants in the control condition. First change scores for the mood scales and for negative/positive affect were calculated by subtracting the mean scores following the BPS/control exercise from the mean scores before the BPS/control exercise. These change scores were then separately entered as dependent variable in a series of ANOVAs with condition (BPS vs. control) as between subject factor. The results of these analyses are summarized in Table 3. There was a statistically significant difference between conditions on change in positive affect $(F(1,38)=5.19, p=0.03)$ indicating that positive affect increased in the BPS condition compared to the control condition. The difference between conditions on change in negative affect was not statistically significant $(F(1,38)=2.51, p=0.12)$. Changes in affect ratings in the BPS and control condition are summarized in Fig. 1.

Next, we tested for differences in change scores on the mood scales between the two conditions. There was a statistically significant difference between the BPS group and the control

Table 2

Correlations among study variables following the negative mood induction.

\begin{tabular}{|c|c|c|c|c|c|c|c|c|}
\hline & 1 & 2 & 3 & 4 & 5 & 6 & 7 & 8 \\
\hline \multicolumn{9}{|l|}{ 1. Positive-negative } \\
\hline 2. Glad-dull & $0.64^{* * *}$ & & & & & & & \\
\hline 3. Secure-anxious & $0.32 *$ & $0.34^{*}$ & & & & & & \\
\hline 4. Happy-sad & $0.73^{* * *}$ & $0.83^{* * *}$ & $0.42^{* * *}$ & & & & & \\
\hline 5. Positive affect & $-0.50^{* * *}$ & $-0.45^{* * *}$ & -0.23 & $-0.35^{*}$ & & & & \\
\hline 6. Negative affect & $0.59^{* * \cdots}$ & $0.51^{* * *}$ & 0.34 & $0.66^{* * *}$ & -0.22 & & & \\
\hline 7. DAS perfectionism & $0.33^{*}$ & $0.36^{*}$ & 0.17 & 0.24 & -0.12 & $0.45^{\text {*** }}$ & & \\
\hline 8. DAS dependency & 0.05 & 0.05 & 0.11 & -0.08 & -0.11 & 0.29 & $0.46^{* * *}$ & \\
\hline 9. DAS total & 0.25 & 0.27 & 0.16 & 0.13 & -0.13 & $0.45^{* * *}$ & $0.90^{* * *}$ & $0.80^{\text {*** }}$ \\
\hline
\end{tabular}

$* p<0.05$.

*** $p<0.01$ (two-tailed). 
Table 3

Effects of the BPS manipulation on positive and negative affect, mood states, and dysfunctional attitudes.

\begin{tabular}{|c|c|c|c|c|c|}
\hline & \multicolumn{2}{|c|}{ Experimental group $(n=20)$} & \multicolumn{2}{|c|}{ Control group $(n=20)$} & \multirow{2}{*}{$\begin{array}{l}\text { ANOVA } \\
F(1,38)^{\mathrm{a}}\end{array}$} \\
\hline & $\begin{array}{l}\text { Pre-test } \\
M \text { (S.D.) }\end{array}$ & $\begin{array}{l}\text { Post-test } \\
M \text { (S.D.) }\end{array}$ & $\begin{array}{l}\text { Pre-test } \\
M \text { (S.D.) }\end{array}$ & $\begin{array}{l}\text { Post-test } \\
M \text { (S.D.) }\end{array}$ & \\
\hline \multicolumn{6}{|l|}{ Mood scales } \\
\hline Positive-negative & $47.65(18.75)$ & $21.40(13.04)$ & $40.50(14.20)$ & $26.75(16.15)$ & $5.29^{*}$ \\
\hline Glad-dull & 59.65 (17.47) & $27.40(14.63)$ & $48.10(15.89)$ & $33.75(16.01)$ & $12.00^{* * *}$ \\
\hline Secure-anxious & $40.95(18.16)$ & $35.65(27.02)$ & $37.20(17.86)$ & 29.45 (13.47) & 0.00 \\
\hline Happy-sad & $55.00(17.45)$ & $23.65(13.24)$ & $42.35(17.76)$ & $28.30(18.66)$ & $8.85^{* * *}$ \\
\hline \multicolumn{6}{|l|}{ PANAS } \\
\hline Positive affect & $49.35(16.52)$ & 64.39 (12.29) & $58.24(15.44)$ & $62.00(20.78)$ & $5.19^{*}$ \\
\hline Negative affect & 24.69 (19.55) & $13.53(12.45)$ & $16.99(15.00)$ & $11.90(11.29)$ & 2.51 \\
\hline \multicolumn{6}{|l|}{ DAS } \\
\hline Perfectionism & $26.80(10.36)$ & $24.25(10.72)$ & $24.10(7.77)$ & $22.00(8.27)$ & 0.12 \\
\hline Dependency & $23.00(6.73)$ & $23.20(7.78)$ & $23.20(6.48)$ & $21.60(6.96)$ & $4.16^{*}$ \\
\hline DAS total & $49.80(15.24)$ & $47.45(16.28)$ & $47.30(11.61)$ & $43.60(12.25)$ & 0.70 \\
\hline
\end{tabular}

$* p<0.05$.

*** $p<0.01$.

a The F-value refers to the differences between the two conditions in change from pre-BPS/control intervention to post-BPS/control intervention. PANAS=Positive Affect

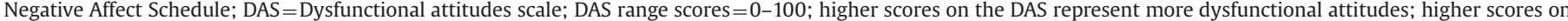

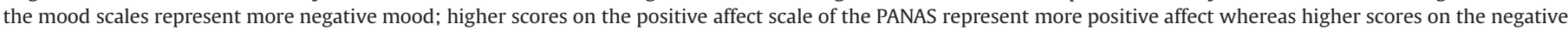
affect scale of the PANAS represent more negative affect.

group on the change scores of three mood scales. Change in the mean rating on the anxious-secure scale did not differ between participants in the BPS condition and participants in the control condition, $(F(1,38)=0.01, p=0.94)$. Changes in the mean of the four mood ratings in the BPS and control condition are summarized in Fig. 1.

\subsection{Effects of the BPS exercise on dysfunctional attitudes (hypothesis 2)}

In order to test hypothesis 2 , we evaluated change in dysfunctional attitudes in participants who received the BPS exercise and participants in the control condition. The results of these analyses are summarized in Table 3. There was a statistically significant difference between conditions on the dependency subscale change score of the DAS, $F(1,38)=4.16, p=0.05$. Participants in the experimental group showed less change on dependency-related dysfunctional attitudes compared to participants in the control group. The difference between the two conditions on the change score of the perfectionism subscale of the DAS was not significant, $F(1,38)=0.12, p=0.73$.

\section{Discussion}

The aims of the present study were to determine the effect of a BPS writing and imagery exercise on positive and negative affect, mood states and dysfunctional thinking patterns in healthy participants. All participants went through a negative mood induction before starting with the experiment. The purpose of the negative mood induction was to trigger negative mood and dysfunctional cognitions in participants and to determine whether the BPS exercise has an effect on affect, mood and dysfunctional cognitions.

Our manipulation check showed that the mood induction had a statistically significant effect on participants' mood as assessed by the four mood scales. It should be noted, however, that on average none of the mood scales were rated very negative following the mood induction. Instead, mood ratings changed from very positive to neutral. This suggests that the mood induction lowered positive mood but did not induce negative mood. In line with this we found that following the mood induction, participants scored statistically significantly lower on the positive affect subscale of the PANAS whereas scores on the negative affect subscale remained the same. Before discussing the results of the BPS exercise, it should be noted that the negative mood induction had a more negative impact on the mood ratings of participants who were randomized to the experimental condition. However, this effect was only apparent on the mood ratings and not on the positive and negative affect scale.

Our first hypothesis was that participants in the BPS condition would experience more positive affect and mood and less negative affect and mood compared to participants in the control condition. In line with our first hypothesis, we found that participants in the BPS condition had statistically significantly higher (i.e. more positive) mood ratings and reported more positive affect, compared to participants in the control condition. This finding is in line with previous studies that experimentally induced optimism in healthy participants (Sheldon and Lyubomirsky, 2006; Peters et al., 2010; Meevissen et al., 2011). Moreover, in the current study we extended previous findings by showing that a BPS exercise can have an effect on positive affect and mood in participants that were experimentally set into a sad mood state. Thus in addition to previous findings (e.g., Peters et al., 2010) showing that the BPS exercise has an impact on positive affect, we also show in the current study that the BPS exercise can reinstate positive affect and mood following a sad mood induction. There was no effect of the BPS exercise on negative affect, suggesting that the BPS exercise increases positive affect and mood but has no effect on negative affect ratings. This finding also replicates previous results showing that induced optimism has no effect on negative affect (Sheldon and Lyubomirsky, 2006; Peters et al., 2010). One explanation for this finding in the current study might be that we failed to induce strong levels of negative affect and mood with the negative mood induction procedure. Different effects of the BPS exercise might be expected in participants with more negative affect and mood ratings (e.g. depressed patients); however this is a question for future research.

Our second hypothesis was that participants in the BPS condition would show decreased dysfunctional attitudes compared to 

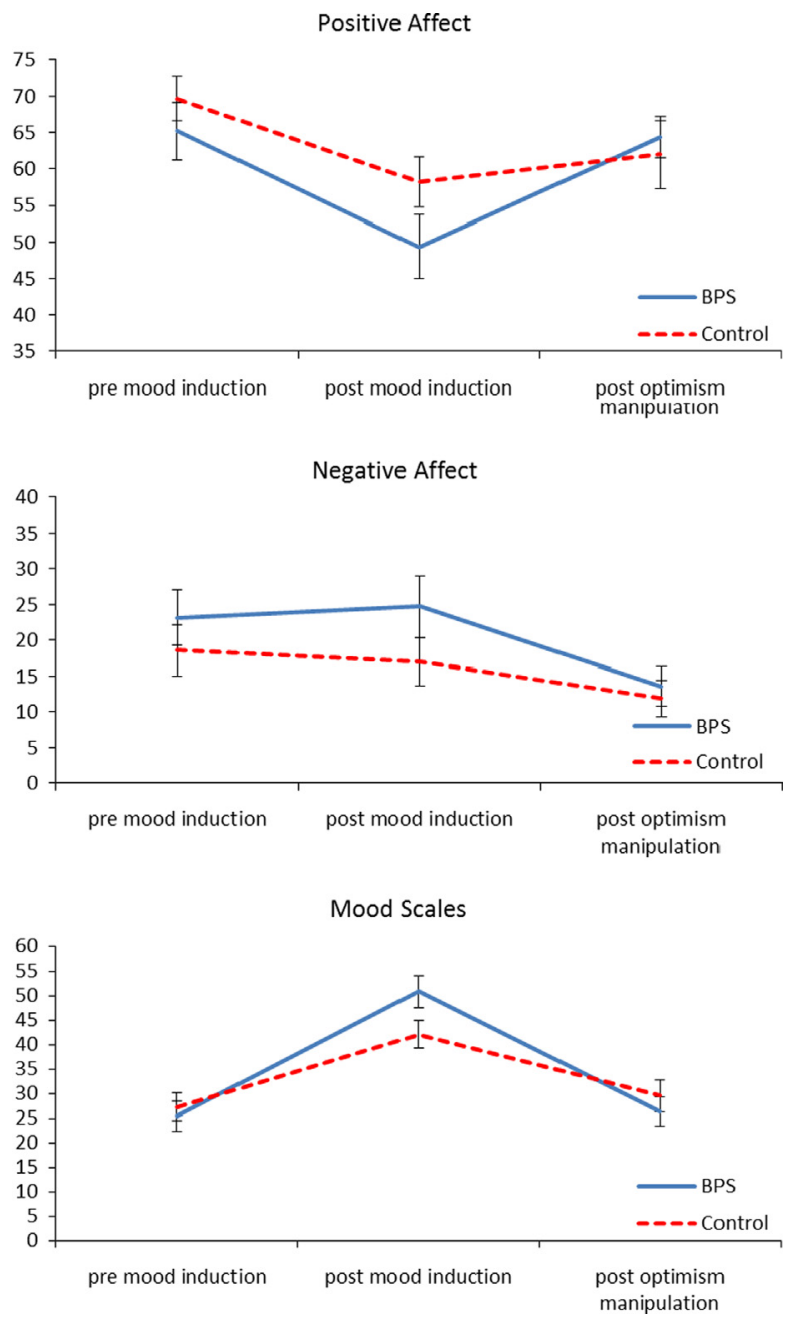

Fig. 1. Change in positive and negative affect and the mean mood ratings in the experimental and control condition throughout the experiment.

Note: Mood scales refers to the average of the four mood rating scales; Higher scores on the positive affect scale represent more positive affect; higher scores on the negative affect scale represent more negative affect; higher scores on the mood scales represent more negative mood; Error bars represent standard error of the mean.

participants in the control condition. Our data did not support this hypothesis. This finding can be explained in the context of the broaden-and-build theory (Fredrickson, 2001). According to this theory, positive emotions triggered by the BPS exercise would be expected to activate an upward spiral that has the potential to ultimately result in decreased negative cognitions. The fact that we did not find a positive effect of the BPS exercise on our cognitive measure might be due to the fact that participants only engaged once in the BPS exercise. Repeated administration of the BPS exercise might be necessary to activate the upward spiral that breaks through negative cognitions. It is also possible that the BPS exercise was not effective in inducing optimism in participants in the experimental condition. However, this explanation is unlikely because the BPS exercise that was used in the current study has been validated in numerous previous studies (Peters et al., 2010; Meevissen et al., 2011; Hanssen et al., 2013; Peters et al., 2013). Finally, in the instructions of the DAS participants were asked to describe how they think most of the time. It is therefore possible, that the DAS assessed trait-like attitudes that do not change as a result of the experimental manipulation. Our results might have differed if we had asked participants to indicate how they think "right now".
There was a statistically significant effect of our manipulation on the dependency subscale of the DAS. However, the direction of this effect was opposite to what we predicted. That is, the dependency score in the control group decreased statistically significantly, while the dependency score in the experimental group remained the same. One explanation for this finding might be that participants in the experimental condition (BPS in the future) were engaged in future-directed thinking and imagery whereas participants in the control condition (a typical day) were probably more engaged in past-directed thinking and imagery. It is possible that reflecting about past events leads to a stronger sense of independence and agency whereas reflecting upon future events leads to a stronger sense of dependence on others because of possible uncertainties that are associated with future events. This explanation is highly speculative and requires further testing. The finding that the dependency score decreased in the control group might also be a type-I error. Future research should aim to replicate this finding to test if this effect is robust.

\subsection{Limitations}

The results of this study should be interpreted in the light of several limitations. First, we assessed dysfunctional attitudes in a relatively small sample of healthy participants following a sad mood induction. The results of this study can therefore not be generalized to clinical populations. Second, we were not able to test whether the negative mood induction had an effect on dysfunctional cognitions in the current study because we did not assess the DAS before the mood induction. Third, the negative mood induction had a stronger impact on mood in participants randomized to the BPS condition and it remains unclear whether this difference had an impact on the effect of the BPS exercise on mood ratings. Fourth, we relied on self-report measures of affect, mood and negative cognitions and it is possible that participants provided social desirable information on these measures. Fifth, although the mood induction led to a decrease in overall mood ratings and to a decrease in positive affect, we were unable to induce negative mood or to increase negative affect with the mood induction paradigm. Effects of the BPS exercise on affect, mood and dysfunctional cognitions might have been different if we had succeeded in inducing negative affect and mood in our participants. Finally, we did not include a measure of optimism in the study and hence we were unable to determine whether the BPS manipulation did in fact increase optimism in the experimental condition. We can therefore not rule out the possibility that the optimism manipulation was in fact just another mood induction. It should be noted, however, that a number of previous studies have already shown that the BPS manipulation reliably induces optimism in undergraduate students (e.g. Peters et al., 2010; Meevissen et al., 2011).

\subsection{Conclusions}

Our findings further support the use of the BPS paradigm as an experimental technique to increase positive affect and mood ratings. Moreover, our findings extend previous studies by showing that the BPS imagery exercise can reinstate positive affect and mood following a sad mood induction. While the BPS imagery exercise might impact positive affect and mood ratings, our data suggest that it has no beneficial effect on negative affect and mood and dysfunctional cognitions in healthy, undergraduate students. Future research should aim to replicate these findings in clinical groups with stronger levels of negative affect and dysfunctional cognitions. 


\section{Acknowledgments}

\section{Maastricht University provided the financial support of this study.}

\section{References}

Abramson, L.Y., Seligman, M.E., Teasdale, J.D., 1978. Learned helplessness in humans: critique and reformulation. Journal of Abnormal Psychology 87, 49-74.

Beck, A.T., 1964. Thinking and depression: II. Theory and therapy. Archives of General Psychiatry 10, 561-571.

Blackwell, S.E., Rius-Ottenheim, N., Schulte-van Maaren, Y.W.M., Carlier, I.V.E., Middelkoop, V.D., Zitman, F.G., Spinhoven, P., Holmes, E.A., Giltay, E.J., 2013. Optimism and mental imagery: a possible cognitive marker to promote wellbeing? Psychiatry Research 206, 56-61.

Carver, C.S., Scheier, M.F., Segerstrom, S.C., 2010. Optimism. Clinical Psychology Review 30, 879-889.

de Graaf, L.E., Roelofs, J., Huibers, M.J.H., 2009. Measuring dysfunctional attitudes in the general population: the Dysfunctional Attitude Scale (form A) revised. Cognitive Therapy and Research 33, 345-355.

Engelen, U., De Peuter, S., Victoir, A., Van Diest, I., Van den Bergh, O., 2006. Verdere validering van de Positive and Negative Affect Schedule (PANAS) en vergelijking van twee Nederlandstalige versies. [Further validation of the Positive and Negative Affect Schedule (PANAS) and comparison of two Dutch versions] Gedrag and Gezondheid: Tijdschrift voor Psychologie and Gezondheid 34, 89-102.

Fredrickson, B.L., 2001. The role of positive emotions in positive psychology: the broaden-and-build theory of positive emotions. American Psychologist 56, 218-226.

Giltay, E.J., Zitman, F.G., Kromhout, D., 2006. Dispositional optimism and the risk of depressive symptoms during 15 years of follow-up: the Zutphen Elderly Study. Journal of Affective Disorders 91, 45-52.

Haaga, D.A., Dyck, M.J., Ernst, D., 1991. Empirical status of cognitive theory of depression. Psychological Bulletin 110, 215-236.

Hanssen, M.M., Peters, M.L., Vlaeyen, J.W.S., Meevissen, Y.M.C., Vancleef, L.M.G., 2013. Optimism lowers pain: evidence of the causal status and underlying mechanisms. Pain 154, 53-58.
Lewis, L.M., Dember, W.N., Schefft, B.K., Radenhausen, R.A., 1995. Can experimentally induced mood affect optimism and pessimism scores? Current Psychology: A Journal for Diverse Perspectives on Diverse Psychological Issues 14, 29-41.

Martin, M., 1990. On the induction of mood. Clinical Psychology Review 10, 669-697.

Meevissen, Y.M.C., Peters, M.L., Alberts, H.J.E.M., 2011. Become more optimistic by imagining a best possible self: effects of a two week intervention. Journal of Behavior Therapy and Experimental Psychiatry 42, 371-378.

Miranda, J., Persons, J.B., Byers, C.N., 1990. Endorsement of dysfunctional beliefs depends on current mood state. Journal of Abnormal Psychology 99, 237-241.

Peters, M.L., Flink, I.K., Boersma, K., Linton, S.J., 2010. Manipulating optimism: can imagining a best possible self be used to increase positive future expectancies? The Journal of Positive Psychology 5, 204-211.

Peters, M.L., Meevissen, Y.M.C., Hanssen, M.M., 2013. Specificity of the Best Possible Self intervention for increasing optimism: comparison with a gratitude intervention. Terapia psicológica 31, 93-100.

Rasmussen, H.N., Scheier, M.F., Greenhouse, J.B., 2009. Optimism and physical health: a meta-analytic review. Annals of Behavioral Medicine 37, 239-256.

Scher, C.D., Ingram, R.E., Segal, Z.V., 2005. Cognitive reactivity and vulnerability: empirical evaluation of construct activation and cognitive diatheses in unipolar depression. Clinical Psychology Review 25, 487-510.

Segerstrom, S.C., Taylor, S.E., Kemeny, M.E., Fahey, J.L., 1998. Optimism is associated with mood, coping, and immune change in response to stress. Journal of Personality and Clinical Psychology 74, 1646-1655.

Sheldon, K.M., Lyubomirsky, S., 2006. How to increase and sustain positive emotion: the effects of expressing gratitude and visualizing best possible selves. The Journal of Positive Psychology 1, 73-82.

Taylor, S.E., Brown, J.D., 1988. Illusion and well-being: a social psychologica perspective on mental health. Psychological Bulletin 103, 193-210.

Taylor, S.E., Kemeny, M.E., Reed, G.M., Bower, J.E., Gruenewald, T.L., 2000. Psychological resources, positive illusions, and health. American Psychologist 55, 99-109.

Watson, D., Clark, L.A., Tellegen, A., 1988. Development and validation of brief measures of positive and negative affect: the PANAS scales. Journal of Personality and Clinical Psychology 54, 1063-1070.

Weissman, A.N., Beck, A.T. 1978. Development and validation of the Dysfunctional Attitude Scale: a preliminary investigation. Paper presented at the 86th annual convention of the American Psychological Association, Toronto, Ontario, Canada. 